\title{
3-D Animation for Planning Crane Operations
}

\author{
Mohamed Al-Hussein ${ }^{1}$, Sabah Alkass ${ }^{2}$, and Osama Moselhi ${ }^{3}$ \\ 1) Ph.D. Candidate,; 2) Associate Professor; 3) Professor and Chair \\ Department of Building, Civil \& Environmental Engineering \\ Concordia University, Canada
}

\begin{abstract}
This paper illustrates the benefits of using 3-D animation in planning crane operations for heavy and critical lifts on construction sites. A methodology for crane selection, location, and on site utilization is presented. The methodology is incorporated into a computer system that integrates a selection module, 3-D animation module, and three databases, dedicated respectively, for cranes, rigging equipment, and project information. This paper describes briefly the essential features of the developed system and its basic components, including its use, for determining the optimum or near optimum selection of crane lift configurations. The paper focuses primarily on the 3-D animation module and its use in planning cranc opcrations. A case example is presented, in order to demonstrate the use of the developed 3-D animation module and to illustrate its essential features. The developed methodology can easily be adapted for evaluation of robots and automated machine in the prototyping stage and later for task planning
\end{abstract}

Keywords: 3-D animation, Database, Crane Selection, planning of critical and heavy lifts.

\section{INTRODUCTION}

Virtual simulation proves to be cost effective tool, in planning crane operations avoiding costly errors in judgement. Computerized systems have been developed for equipment selection in general (Alkass et al. 1993, Moselhi and El Ghazal 1992, and Christian et al. 1987), and for cranes in particular. Computer modules were developed, for planning heavy and critical lifts using integer programming (Lin et al 1996-A and Lin et al 1996-B), 3D graphics and computer simulation (Hornaday et al 1993, Williams and Bennett 1996, Dharwdkar et al 1994, and Al-Hussein et. al 1998). Database management systems have also been used to support crane selection and lift planning (Haas and Lin 1995; and AL-Hussein 1995). Despite the usefulness of these systems, none provide solutions for the selection and location of cranes in a holistic manner.

This paper presents a multimedia crane selection methodology, designed to assist practitioners and engincers in planning crane operations. The methodology has been incorporated into a computer system, involving a crane selection module, supported by 3-D graphics, and three databases dedicated for cranes, rigging equipment, and project information. The crane database contains information on 48 different crane models, varying in capacitics from 20 tones to 880 tones. This set of cranes provides 209 options of different crane lift configurations, each has a number of lift capacity settings. Those lift capacity settings range in number from 63 to 5,197 per crane configuration. This makes the total number of stored crane lift configurations and their capacity settings in excess of a hundred thousand. The rigging database contains information on rigging equipment including slings, shackles, and spreader beams. The project information database is essentially a transactional database, designed to store information about projects, clients, and names of participants. The selection module, which uses these databases, has been developed using MS-Visual Basic programming language. This paper focuses on the use of 3-D animation for planning lift operations and crane utilization on construction sites. The 3-D animation has been developed using 3D-Stodio animation, based on AutoCAD 3-D solids, which represents the physical site layout and crane components. A case example is presented to demonstrate the effectiveness of the developed methodology and to illustrate the essential features of the developed 3-D animation. The case concerns the replacement of the corroded main burner top portion (Digester Retrofit) for a paper pulp manufacturer, located in Lebel-SurQuevillon, Quebec, Canada.

\section{PROPOSED SYSTEM}

\section{Overview}

The selection methodology including a detailed description of the systems' selection module has becn dealt with elsewhere (Al-Hussein et al 1998), and will be briefly described in this section to provide 
continuity. The methodology has been developed utilizing current industry practices. This was carried out through site visits, interviews with experts, and study of past projects. Figure 1 illustrates the systems' architecture and its data flow. Essentially, the developed methodology searches for the least cost cranc configuration that is technically feasible. Crane configuration and lift settings are evaluated for their capabilities to place the lift in its final position. They are identified based on their respective load capacity as retricved from the crane database. Technically feasible crane configurations are listed in a descending order based on their rental cost, and accordingly the least cost option could be identified.

The cranc sclection process starts with entering the data pcrtaining to the lift, the building and the site being considered. The lift weight and size determines the rigging equipment. After knowing the total lift wcight (lift and rigging equipment), the selection modulc queries all crane configurations and their settings from the crane database. These cranc configurations can perform the lift, accounting for the geometric constraints associated with the lift and the site. To reduce unnecessary computations and increase the speed of the search through thousands of records, the selection module queries only crane configurations and their lift settings, which are capable of lifting the total lift weight, or exceedjng it in increments of $20 \%$.

\section{D-Animation Module}

AutoCAD 3D-Solids was utilized to represent the physical site layout and crane components. The developed system currently has 12 different crane models drawn in A.utoCAD-3D. The geometry of these cranes are stored in the 3-D module database, these cranes vary in capacities from 140 tones to 880 tones (five (5) conventional, five (5) hydraulic, and two (2) crawler cranes). This set of cranes provides 76 options of different crane lift configurations. To reduce the AutoCAD operators' time in assembling the cranes' components for a new job, these crane configurations were further assembled and joined together to match the configuration required for different lift settings. These assemblies are defined to represent different boom lengths for lattice boom (conventional boom) configurations and different jibs/extensions lengths as wcll.

The best way to illustrate the advantages of using a 3$D$ module is through the use of a case example. The case demonstrates the added values of the developed 3 D, module in:

1) Performing front-end planning prior to the deployment of cranes on site.
2) Provides users with on screen visualization of the entire operation.

3) Multiple views could be generated from one 3-D drawing.

4) Expedites the safely officers' work of approving lifting plans.

The site in the case considered was congested, and a number of special arrangements had to be done. The crane's outriggers had to be set between existing reservoirs and nearby facilities, and their pads (steel plates used to distribute the total load of the crane and the lift to the ground) had to be rotated to fit the cranes' outriggers on sitc. This necessitated engineering analyses, evaluation and approval prior to the execution of the lift.

\section{CASE EXAMPLE}

The case considered involves the replacement of the top portion of the main burner for a paper pulp manufacturer, located in Quebec, Canada. Gases from the burned material in the main burner cause corrosion to its top portion, a common problem in the pulp and paper industry particularly for plants built during the past four decades. The only feasible solution to the problem is to cut and replace its top portion, which weighs $165,344-\mathrm{lb}(75,000 \mathrm{~kg})$ and is cncased within a $225-\mathrm{ft}(67 \mathrm{~m})$ high facility. This solution requires selecting an appropriate crane to perform the lift. The site in this case was congested. The burner is located within the 225 ft $(67 \mathrm{~m})$ high facility, surrounded by other buildings, which obstructed the crane reach. These obstructions added $51-\mathrm{ft}(15 \mathrm{~m})$ of horizontal distance at a height of $80-\mathrm{ft}$ (24 m).

The lift weight and its key dimensions are entered first as shown in Figure 2. Then the user is provided with an option to select the rigging cquipment from those stored in the rigging database or, alternatively, enter the height and the weight of the rigging of his/her choice. Unless cntered by the user the selection module generates a default value for the rigging's weight and height as $10 \%$ of the lift weight and $10 \mathrm{ft}(3 \mathrm{~m})$, respectively. For this particular casc two slings $36-\mathrm{ft}(10.97-\mathrm{m})$ long, weighing 3,249-lb $(1,473.75-\mathrm{kg})$, and a $5,000-\mathrm{lb}(2,268-\mathrm{kg})$ hook block were selected. The shape of the building, the final lifts location, and the site constraints are entered next as shown in Figure 3. 


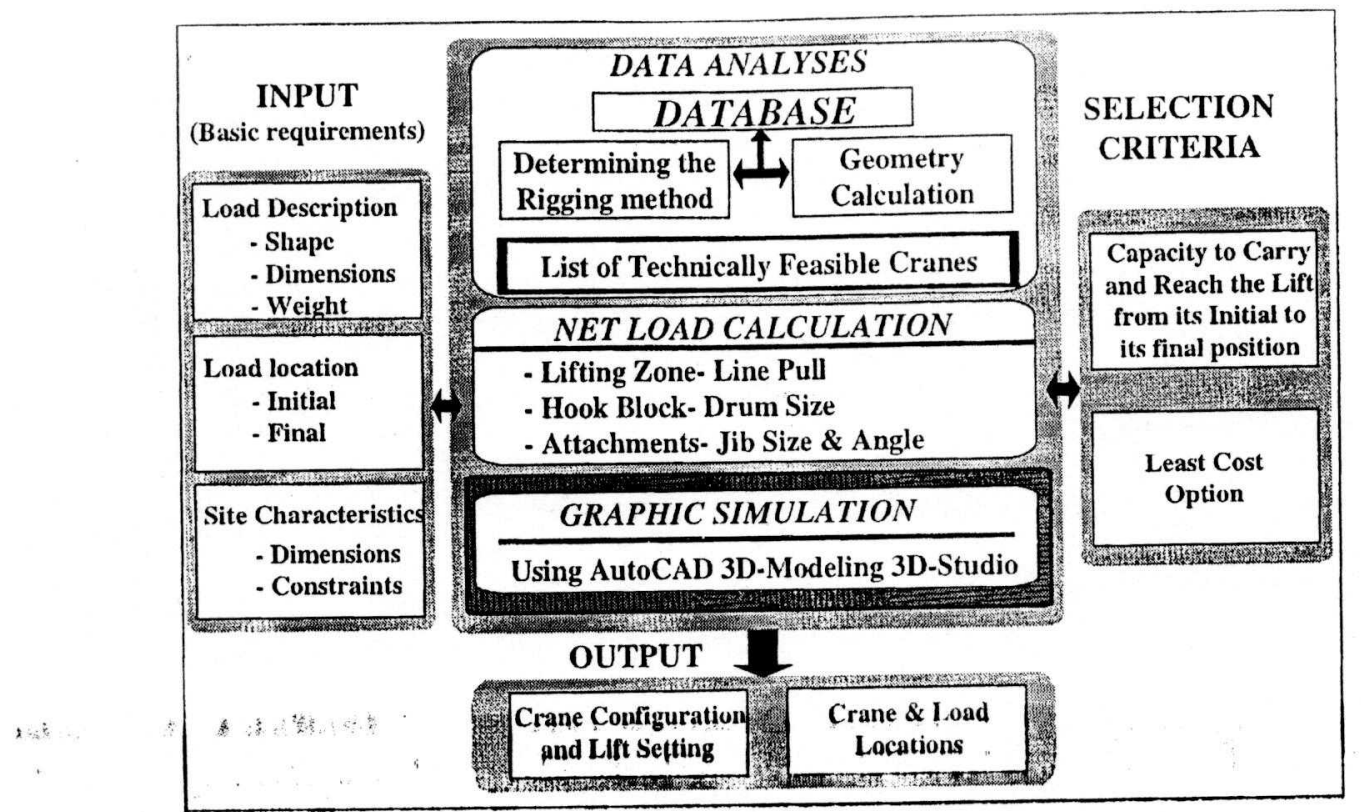

Figure 1 System's Architecture

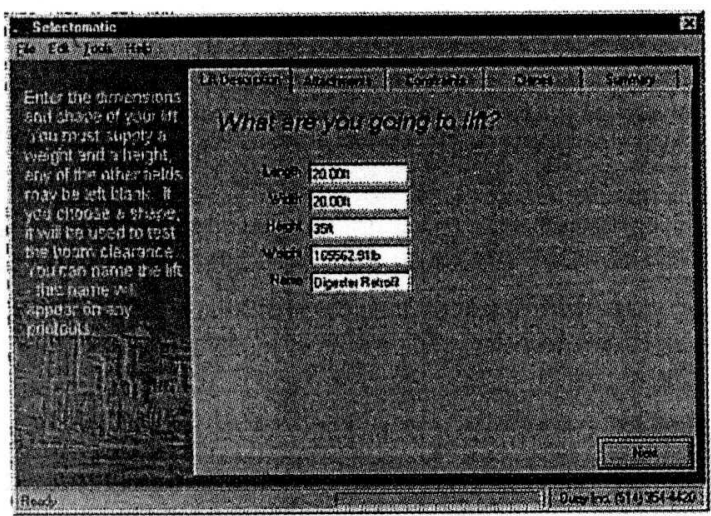

Figure 2 Weight Evaluations Screen

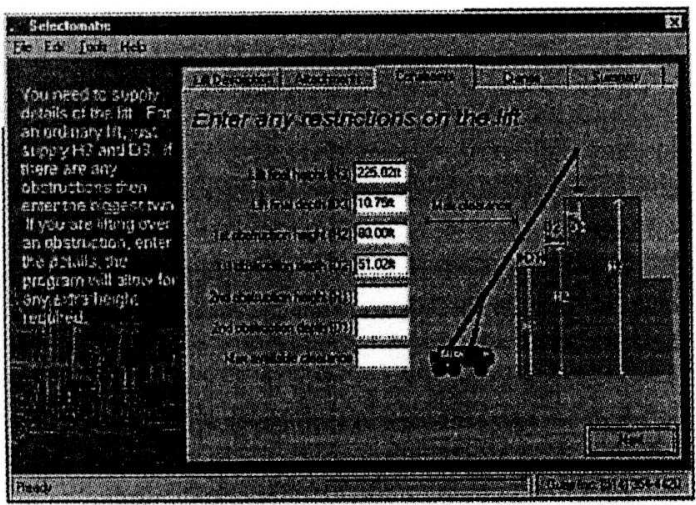

Figure 3 Site Evaluations Screen
The search for technically feasible crane configurations and their settings starts by choosing the "list cranes" option, shown in Figure 4. The list contains 11 different settings, that are capable of lifting the load. These lift settings are generated from two configurations of the Demag TC 4000 crane (i.e. lifting on the main boom and a main boom with a luffing $\mathrm{jib}$ installed). The highlighted Demag TC 4000 with boom length of $354-\mathrm{ft}(107.89-\mathrm{m})$, a radius of $112-\mathrm{ft}(34.14-\mathrm{m})$, and a lifting capacity of $174,000-\mathrm{lb}(78,926-\mathrm{kg})$ was selected. To limit the search, and increase the searching speed the selection module provides the following: 1) limiting the scarch by choosing a manufacturer's name; 2) selecting a particular crane model; 3) selecting a crane type (conventional or hydraulic); and 4) choosing a particular boom and/or jib length. This step ends by displaying a list of technically leasible crane configurations and their lift settings, ranked in a descending order based on their rental costs. Upon choosing a particular crane configuration and a lift setting from the list, more details about these particular configuration and lift settings are displayed in the sunmmary screen, which includes the type of crane, lifting radius, tip height, boom and jib lengths, boom and jib angles, clearances, and crane capacity. Finally a report is produced, that includes a summary of relevant information about the project, crane configuration, lift capacity, client, and names of participants, along with a $2 \mathrm{D}$-elevation view of the 
crane and the building. The report contents are stored in a separate transactional project database.

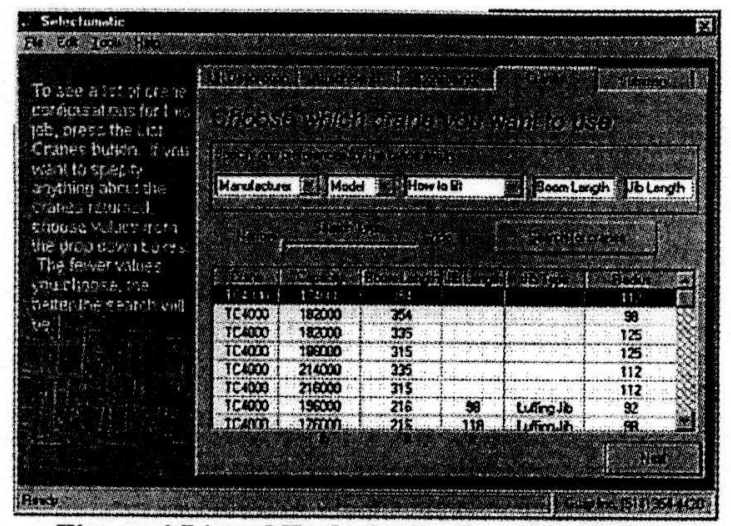

Figure 4 List of Technically Feasible Cranes Screen

The site in this case was congested creating the following three problems:

1) The crane's outriggers and pads had to be set between existing reservoirs and nearby facilities.

2) The plan was to swing the crane $300^{\circ}$ degrees in order for it to carry the lift to its final position, and due to site accessibility problems, the initial lift pick-up was limited to that planned location.

3) The boom clearance to the obstruction is only $2-\mathrm{ft}(0.61 \mathrm{~m})$, which is a small distance for such a crane with a 354-ft long main boom configuration at a $112-\mathrm{ft}$ radius, working within its full capacity. This crane uses a conventional (lattice) boom, which allows for deflection, that is not considered in the developed crane selection module.

The 3-D module was used to assist in solving these problems and to produce lifting plans for the approval of the engineers and safety officers. The selection module sited above advises on selecting the Demag TC4000 with boom length of $345-\mathrm{ft}(107.89 \mathrm{~m})$ at working radius of $112-\mathrm{ft}(34.14 \mathrm{~m})$. The system's solution suggested is presented in a 3-D context, representing the physical site layout and crane properties using a 3-D AutoCAD Solid modeling system. AutoCAD 3D Solids drawing were transferred to the virtual simulation software 3DStodio, which allows on screen visualization of to the entire operation, depicting the crane relative position and its components to the nearby facilities. The 3-D animation module shows that the crane's mats have to be rotated to fit the cranes' outriggers on site between the existing rescrvoirs and nearby facilities as shown in Figure 5.

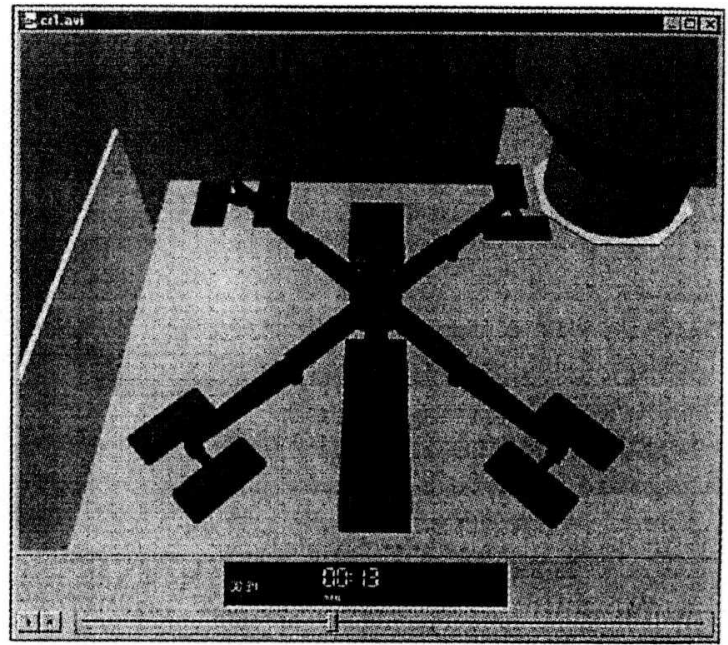

Figure 5 Plan View of the Case Study

The 3-D animation module shows also that the tail swing of the crane will collide with the nearby building, as a result, the site has to be cleared and the lift has been delivered to a new location within the allowable radius of $150^{\circ}$, not $300^{\circ}$ degrees as originally planed. Figure 6 shows the tail swing of the crane.

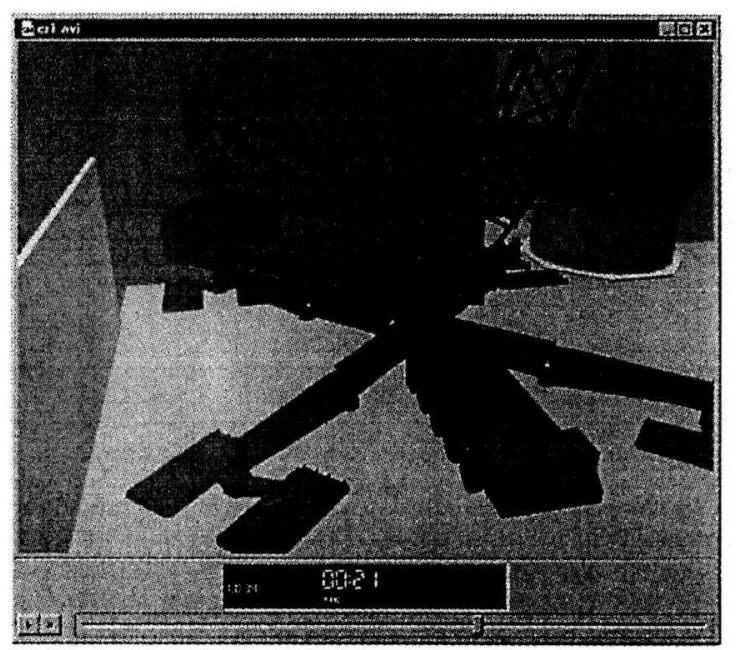

Figure 6 3D View of the Case Study

The view shown in Figure 7 demonstrates also that the main boom of the crane is passing at a very small distance, from the wall of the adjacent facility. The 3D animation model provided a robust visualization tool, helping to reveal the fact that the cladding of the building had to be removed to prevent a potential collision between the deflected main boom and the wall. As a result, the wall was stripped down prior to the cranes' arrival as shown in Figure 8. 


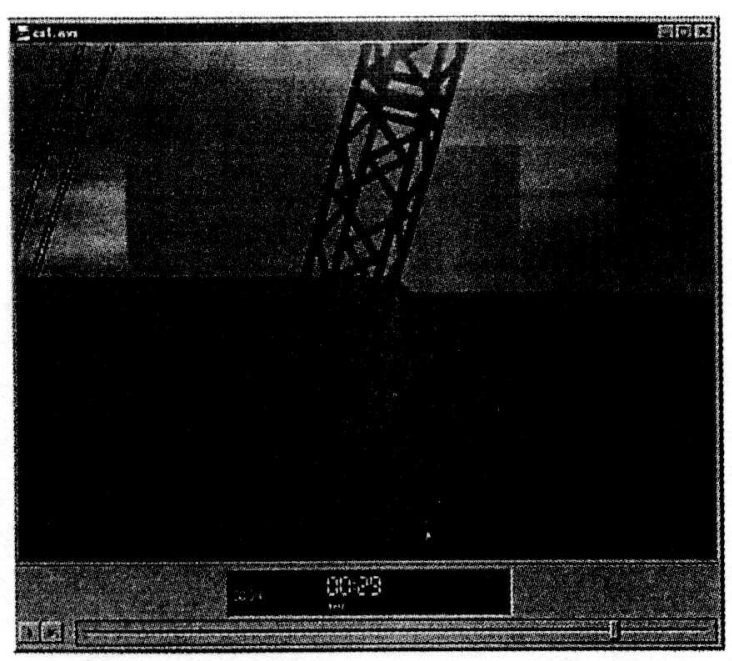

Figure 7 Elevation View of the Case Study

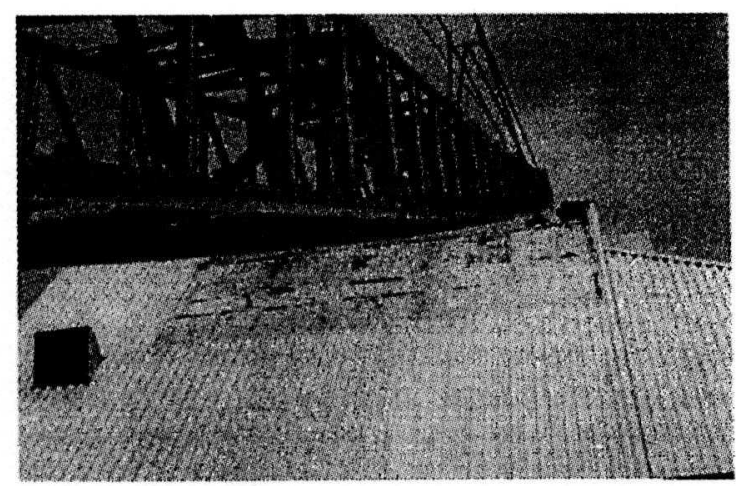

Figure 8 Actual Picture Showing the Boom Deflection \& the Removed Cladding

Failure to identify these necessary on-site changes would have clearly resulted in cost over-runs as the crane would have had to sit idle while waiting for the claddings to be removed and for the engineering approval for the rotation of the cranes' pads. Guesswork was reduced and unsafe and time consuming on-site testing was avoided. In addition, the delivery and arrival of the cranes' carrier to the site was delayed by four (4) days duc to an engine problem, that occurred while traveling the distance of $600 \mathrm{~km}$ from Montreal to the project site. A crew of four (4) operators and all crane components, except the carrier, were sent to the site, along with two (2) cranes to erect the selected crane. Based on the drawings generated by the 3-D animation module, the crane operators were able to erect the components of the crane while waiting for the crane's arrival. This resulted in considerable cost saving for the company.

The concept of 3-D modeling and animation has also increased the efficiency of designers and planers.
Once the site is drawn in 3-D and the crane and lift are placed, the planner can easily generate any number of views for evaluation and assessment prior to the approval of the planes for executing the lift. The clients' engineers and safety representatives received the report along with nine (9) different 2-D and 3-D drawings of the lift operation, along with the 3-D animation file to show the entire crane operation similar to this shown in Figure 9. This expedites the work of safety officers in order to facilitate approval of the lifting plans.

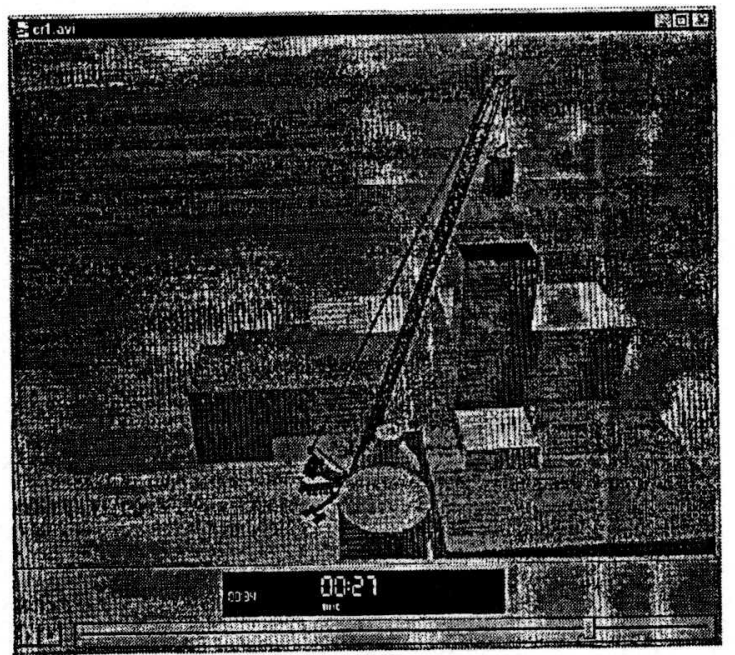

Figure 9 Site View From the 3DAnimation

\section{SUMMARY AND CONCLUDING REMARKS}

An automated system for planning of heavy and critical lifts using cranes has been presented. 'The paper focused on the use of 3-D graphics to support planers in executing this class of lifts. The developed module provides 2-D and 3-D graphics, so as to support the visualization of the planed lift from start to completion. The developed system integrates 3-D graphics, selection module, and three databases. The 3-D graphics module has been developed using AutoCAD 3-D Solids. A case example was used to demonstrate the effectiveness of the developed methodology in avoiding potential accidents and in reducing the time and cost associated with the planning of heavy and critical lifts on construction sites. 


\section{ACKNOWLEDGEMENTS}

The financial support of the Natural Science and Engineering Research Council of Canada and that of the industrial partner, GUAY Inc. is gratefully acknowledged. The authors wish to specifically thanks Jean MacDonald (former Branch Manager of GUAY Inc.); Pascal Bouliane, Engineer GUAY Inc.; Donald E. Dickie, Assistant General Manager of the Construction Safety Association of Ontario; for their time, effort and valuable information.

\section{REFERENCES}

Al-Hussein, M., Alkass, S., and Moselhi, O., (1998) "Decision Support System for Crane Selection and Location on Construction Sites", Proc. of the First Int. Conf. on New Information Technologies for Decision Making in Civil Engrg., Vol. 2, pp. 1253-1264.

Al-Hussein, M, (1995) "A Computer Integrated System for Crane Selection for High-Rise Building Construction", M.A.Sc. Thesis, Centre For Building Studies, Concordia University.

Alkass S., A. Aronian and O. Mosclhi, (1993) "Computer Aided Equipment Selection For Transporting and Placing Concrete", J. of Const. Engrg. and Mgmt., Vol. 119, No. 3, pp. 445-465

Christian, J., and Caldera, H., (1987) "The Development of a Knowledge Based Expert System for the Selection of Earthmoving Equipment", AICivil-Comp, Proc., 3rd Int. Conf. on Struct. and Civil Engrg. Computing, Civil-Comp Press, Edinburgh, UK, pp. 55-59.

Dharwadkar, P. V., Varghese, K., O'Connor, J. T., and Gatton, T. M. (1994). "Graphical Visualization for Planning Heavy Lifts". Proc. Of the $3^{\text {nd }}$ Congress on Comp. Civil Engeg., K. Khozeimeh, ed. ASCE, New York, N. Y.

Haas, C. T., and Lin, K. (1995). "An Interactive Database System with Graphical Linkage for Computer Aided Critical Lift Planning." Proc., of $12^{\text {th }}$ Int. Symp. on Automation and Robotics in Constr. (ISRC), Warsaw, Poland, 313-324.

Hornaday, W. C., Haas, C. T., O'Connor, J. T., and Wen, J. (1993). "Computer-Aided Planning for Heavy Lifts", J. Constr. Engrg. and Mgmt., ASCE, 119(3), 498-3515.

Lin, K. L., and Haas, C. T. (1996-A). "Multiple Heavy Lifts Optimization." J. Constr. Engrg. and Mgint., ASCE, 122(4);'354-361.

Lin, K. L., and Haas, C. T. (1996-B). "An Interactive Planning Environment for Critical Operations." J. Constr. Engrg. And Mgmt., ASCE, 122(3), 212-222.
Moselhi, O., and El Ghazal, N., (1992) "A Knowledge Base Approach for Selection of Earthmoving Equipment", Proceedings of the Canadian Conference and Exhibition on Industrial Automation, Montreal, Canada, pp. (1.9) - (1.12).

Williams Mike, and Bennett Craig (1996) "ALPS: The Automated Lift Planning System", Proc. of the $3^{\text {rl }}$ Congress on Comp. Civil Engrg., New York, N. Y. 